\title{
The Role Played by Socio-Cultural Factors in Sports Consumer Behavior
}

\author{
${ }^{1}$ Hossein Abdolmaleki, ${ }^{2}$ Zahrasadat Mirzazadeh ${ }^{*},{ }^{3}$ Ebrahim Alidoust Ghahfarokhhi \\ ${ }^{1}$ Department of Sport Management, Faculty of physical education and sport science, Karaj Branch, Islamic Azad \\ University, Karaj, Iran. ${ }^{2}$ Department of Sport Management, Faculty of Sport Sciences, Ferdowsi University of Mashhad, \\ Mashhad, Iran. ${ }^{3}$ Department of Sport Management, Faculty of Sport Sciences, University of Tehran, Tehran, Iran.
}

\begin{abstract}
One common aspect of all human beings, regardless of education level, income level, location and so on, is that they are all consumers. The key of success in marketing strategy both in terms of local and global aspects is understanding consumer behavior. So aim of this study was to investigate the role of socio-cultural factors on sports consumer behavior. This research was survey- descriptive. The study population were included all sports consumers in Tehran. The sampling method was random. Based on the PASS statistical software, research sample size was determined in the range of 321 to 384 people. Data collection instrument was two questionnaires. The validity was content validity and construct validity. In order to data analyzing was used Path analysis and analytic hierarchy process (AHP). The results showed that social factors (social class, idea leaders, family and references group) and cultural factors (culture and religion) have a significant positive effect on sports consumer behavior. Also sociocultural factors prioritize results showed that social class with the relative weight of 0.391 is the most important component. In this study found companies to gain competitive advantage should have be given to customers and meet their needs (better than competitors). In addition, customers buy products with different trends that should be considered in formulating marketing strategies.
\end{abstract}

KEY WORDS: Consumer Behavior, Idea Leaders, References Group, Sport Marketing.

\section{INTRODUCTION}

In recent decades, the expansion and development of sporting business events by economic enterprises have been achieved in the form of using sport as a means for ensuring the prosperity and development of business and commercial activities worldwide so as to access international markets (1). This process is not unique to athletic and professional sporting events and many of them are true even for (apparently) amateur sports (2). The sports industry has quickly become global in its reach, and its domain has developed everywhere and has expanded across the world, for the use of billions of people (3). The importance of sports for the economy increases every day, so that sports have become one of the most profitable sectors of the economy (4). Production of sporting goods now is one of the important industrial areas with various subsets, and its domain is expanding day by day. Economically

*. Corresponding Author:

Zahrasadat Mirzazadeh

E-mail: z.mirzazadeh@um.ac.ir 
important sectors like sports tourism, sports companies and centres, organization of great sport conferences, the marketing industry, recreation, advertising, sport clubs and finally sports itself are the most important areas of the economy that are linked to sports. Orientation towards the market and achieving success under the aegis of such orientation are, at present, the most important goals of sports. The consequence of this process is further integration of sports with the economy in various forms. This integration has caused the sporting economy to become more important (5). On the other hand, in today's competitive world, companies primarily focus on customers and the satisfaction of their customers is the main factor in gaining competitive advantage. The necessity for obtaining customer satisfaction is to supply their needs completely and to identify the needs, desires, expectations, abilities and their limitations accurately in providing and purchasing products. With access to such information, one can recognize factors influencing customers' behaviour of service organizations as well and use them in marketing decisions of companies (6).

One of the common features of all people, regardless of education level, income level, place of living and so on, is that all of us are consumers. This means that we consume or use food, clothing, housing, etc, based on a certain order. The key point for success of marketing strategy, both in terms of local and global aspects, is to understand the consumer's behavior (7). This fact is applied both to firms and non-profit organizations and government agencies that enact laws of marketing. However, understanding the consumer's behavior and evaluating the performance of consumers in various communities is also of particular importance due to cultural differences (8). On the other hand, the existence and survival of all creatures and systems are related to enough input and consumption of resources, because any system and creature does not exist without consumption of resources. But what is important in the field of the existence and survival of systems is survival combined with success, and one of things that help successful and unique survival of each system is the degree, level and the way of using related sources. Especially in the meantime in human entities, how to use facilities and resources has an important and strategic role in taking steps towards perfection (9).

Since successful sports marketing started with an understanding of why and how the behaviours of consumers and sport audiences occur, the understanding of the factors influencing sport consumers' preferences and behaviours can be considered the basis for decisions of sports consumers. The sports consumer's behaviour includes psychological and social processes which are there before and after the audiences' activities that tend towards various sporting products. How sports audiences think, how they behave, what factors influence their tendency towards different sport products, and other questions of this kind are the key to the development of effective marketing programmes so that the organization and organizers of sporting events can achieve non-predetermined goals (10).

In this regard, Kharazmi, Forghani Ozrudi, and Amani (2015) reported that the quality of services and the quality of the product had the most importance for male and female athletes. These results show that those individuals are inclined to use and buy branded sport clothing that are looking for sale services such as seasonal auctions, warranty of the product, giving gifts in occasions, and also the quality of sport clothing (11). Sadeghi et al. (2013) showed that there were significant differences between consumers and sellers, and also between manufacturers and sellers in relation to the reasons of using the external sport products, but there was no difference between consumers and producers. From the perspective of consumers, the higher compliance of external sport products with the sport standards, the quality and durability of external sport products, and weak advertising by domestic producers about the characteristics of their products in media versus widespread advertising of foreign producers are respectively the most important reasons (12). Behnam (2015) concluded that the main effects of the promotion of applying services on attitudes towards propaganda in subjects that have observed the advertising by promoting the application of free services are higher than those of subjects that have observed similar advertising without promoting the experimental services and have more positive attitudes (13). Davies and Cline 
(2005) identified and introduced five characteristics of the market-product that can influence the consumer's decision-making process. These five features include: market size, the difference between markets, the boundaries of the market, the difference between the brands and retail (9). Tatt (2010) showed that perceived social status, quality and brand loyalty are significantly related to the factors influencing consumers' purchasing behavior, while price had not a significant relationship. The results also indicated that the monthly income is not an appropriate mediator between the independent variable (brand loyalty) and the dependent variable (purchasing behavior) (14). Yee and Sidek (2008) reported that brand name, product quality, price, advertising, product diversification, quality of service and sport apparel retail environment influence purchasing behavior of sport clothing consumers (15).

Also, given the growth in marketing and the role of sports and sporting products in creating specific behaviour patterns that attract consumers and develop a consumer base, an investigation is necessary into consumers' behaviour in this area. Therefore, the marketing professionals need to search and find suitable markets and sectors wherein the organization can be present more usefully and effectively. Hence, the foundation of the marketing movement is to prevent wastage of different resources and facilities and find the most suitable place for the product. On the other hand, in the aspect of finding markets, the most important efforts of marketers are to attract, develop and retain their target market (customer, product, etc.) i.e. market penetration and the introduction and recognition of the organization, products and services using the marketing mix (product, price, distribution and promotion) (6).

Meanwhile, consumers are considered target markets of sports organization. This group is considered the main pillar of the sports industry to determine how the demands of the present can be satisfied and typically their attraction and development are the most important principles in the field of sport marketing. This shows why people call for financial, emotional and time investments for participation in sports. Marketing research has shown that the cost of attracting new customers is 5 to 11 times the cost of maintaining the current customers, and the loss in missing a customer is equal to the loss of 100 more customers (16). The identification of environmental and individual factors has a great impact on the success of sports marketers. There are some factors over which sport marketers have limited control. However, these can affect the interests of the respective sport organizations. However, no model of the impact of social factors on consumer behaviour in the sports industry has been provided so far. The aim of this research, therefore, is to study the role of sociocultural factors in consumer behaviour in relation to the issue of sporting products.

\section{MATERIALS AND METHODS}

Participants. The population of the study consisted of all sport consumers in Tehran that purchase sporting goods. The selection of the sample was done using random sampling method. Based on the PASS statistical software, the sample size was determined in the range of 321 to 384 people. According to the population with a probability of 5 percent loss, 400 questionnaires were distributed to the population. At the end, after the elimination of incomplete questionnaires, 376 questionnaires were used for statistical analysis of data.

Tools. Data collection instrument was the researcher-made questionnaire with 34 items as follows: The first part of the questionnaire consisted of six items related to demographic variables including age, gender and level of education, etc.

The second part of the questionnaire consisted of 28 items; four items were related to family, four items related to the reference groups, four items related to social class, four items related to opinion leaders, four items to culture, four items to religion and four items related to consumer's behavior. Each of the items has a 5-point Likert scale from strongly agree $=5$, agree $=4$, no idea $=3$, disagree $=2$ and strongly disagree $=1$. Also to prioritize the factors influencing consumer's behavior were used another questionnaire that filled by 12 sport marketing elites.

The validity of the questionnaire was content validity and construct validity. The content validity of the questionnaire was approved by 12 members of the sport marketing elites. Exploratory factor 
analysis was used to confirm the construct validity. To evaluate the reliability of the questionnaire, given the existing limitations, 30 questionnaires of the distributed questionnaires were randomly chosen and were analyzed using the SPSS statistical software and Cronbach's alpha coefficient that reliability of the questionnaire obtained equal to 0.83 that according to the value of the coefficient, it can be said that the questionnaire has high reliability for this study.

Data Analysis. In order to analyze the data, path analysis and analytic hierarchy process (AHP) were used.

\section{RESULTS}

Descriptive results of research show that: 253 people were man and 123 of them were woman. About partiality 179 people was Persian, 113 people Turk, 38 people Lor, 16 people Kurd and 30 people was other partiality. About monthly income, most of them (278 people) has average income (between 1.2 to 1.9 million Toman).

Before providing the Inferential statistics of components of the research, the construct validity of the questionnaire was examined by confirmatory factor analysis. Then, in Figure 1, the output Amos Graphics Software, Confirmatory factor analysis of consumer behavior questionnaire and sports are shown. As you can see, all 6 components in this model have the appropriate Standardized Estimates loads (in level of 0.001 error) are, thus confirming previous results. The reliability of structures with respect to the reliability of supplies (11.58) and variance extracted (3.67) was confirmed.

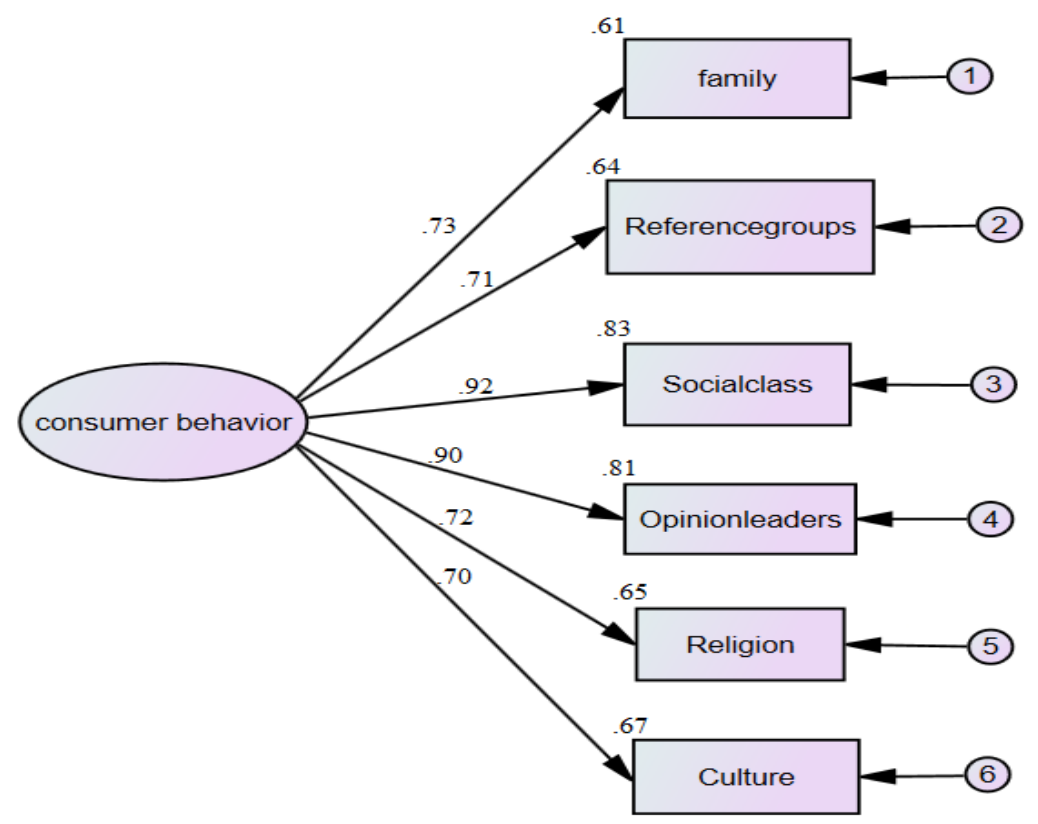

Figure 1. Confirmatory factor analysis of questionnaire

In order to provide structural equation model in this study, AMOS software was used that the results are reported in the following. The results of the proposed model show the fitness of the model for data. Using the terms of the chisquare and other appropriate statistical indicators, the fitness of the model is as shown in Table 1.

Table1. Indicators of model fitness

\begin{tabular}{cccccccc}
\hline & $\mathrm{X}^{2} / \mathrm{df}$ & CFI & NNFI & NFI & GFI & AGFI & RMSEA \\
\hline Amount & 2.91 & 0.987 & 0.976 & 0.934 & 0.955 & 0.913 & 0.047 \\
Criterion & $<3$ & $>0.90$ & $>0.90$ & $>0.90$ & $>0.90$ & $>0.90$ & $>0.05$ \\
fitness Interpretation & Good & Good & Good & Good & Good & Good & Good \\
\hline
\end{tabular}


Figure 2 also shows the proposed research model. The results for the

factors of the effect of components are shown in Table 2 .

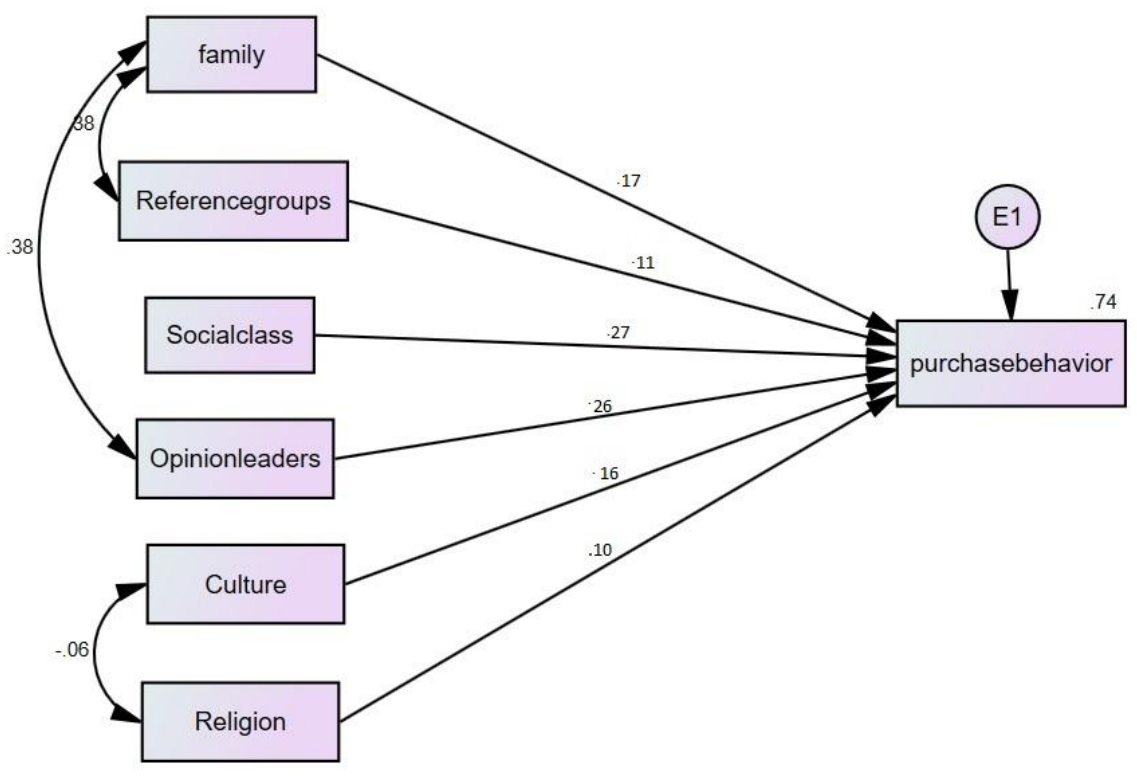

Figure 2. The proposed model

Table2. The path factors of the components of the research model

\begin{tabular}{lccccc}
\hline \multicolumn{1}{c}{ Path } & $\begin{array}{c}\text { Estimation of } \\
\text { parameter }\end{array}$ & SE & $\begin{array}{c}\text { T- } \\
\text { test }\end{array}$ & $\begin{array}{c}\text { Standard } \\
\beta\end{array}$ & Sig. \\
\hline Family-Purchase Behavior & 0.101 & 0.052 & 1.922 & 0.168 & Confirmed \\
Social Class- Purchase Behavior & 0.080 & 0.057 & 1.983 & 0.113 & Confirmed \\
$\begin{array}{l}\text { Reference Groups- Purchase } \\
\text { Behavior }\end{array}$ & 0.213 & 0.071 & 3.023 & 0.271 & Confirmed \\
$\begin{array}{l}\text { Opinion Leaders- Purchase } \\
\text { Behavior }\end{array}$ & 0.193 & 0.067 & 2.876 & 0.267 & Confirmed \\
Culture- Purchase Behavior & 0.099 & 0.045 & 3.765 & 0.161 & Confirmed \\
Religion- Purchase Behavior & 0.078 & 0.049 & 2.334 & 0.102 & Confirmed \\
\hline
\end{tabular}

As well as to prioritize the factors influencing consumer's behavior, the analytic hierarchy process was used that the results are shown in Figure 3. The results of prioritization of components of social factors indicate that the social class with the relative weight of 0.391 is the most important component of social factors and then are Opinion Leaders (0.276), Family (0.195), Reference Groups
(0.138), Culture (0.187) And Religion (0.125) respectively.

\section{DISCUSSION}

In this study, it was found that the consumer's social class plays a significant positive role in the behaviour of consumers of sports products. It was the most important factor affecting sporting consumer behaviour. 


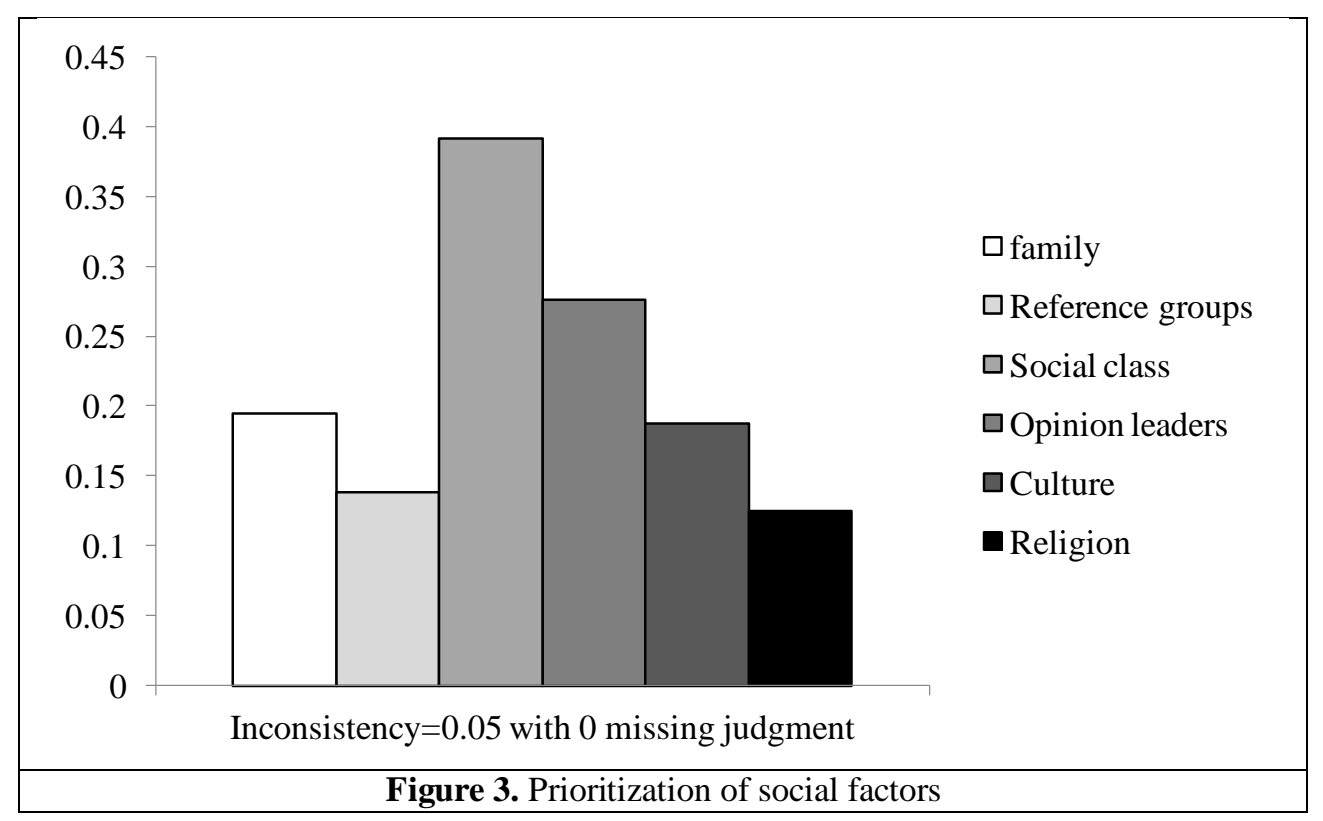

In the present study, subjects have expressed their opinion that they purchase a product that is at their social level and which they can afford to purchase. Anastasiadou (2014) noted that social class has not merely been an economic measure, but also includes a variety of concepts such as prestige, position, and sense of common belonging. Generally, members of a social class tend to live in a similar way, have common attitudes and philosophy, and-most importantly-have similar consumption paradigms (17).

However, consumption paradigms are not necessarily similar. In this study, social class is an important indicator to specify the type of consumption. In fact, some believe that the society is the most important and the best indicator of consumer's behaviour in his/her response to incentives and propaganda. End and Foster (2010) stated, however, that people often dislike the idea that some people are better than others and are different from them, but in fact, most consumers are aware of the existence of different social classes and the impact of membership of a class on consumption (2). In this study, researchers found that since the consumers of different classes have different preferences about spending money and time, consuming societies can be considered the reason for purchase and use. In addition, the social class also influences the type of consumption, because we create impressions of people by their types of consumption. Hassangholipour et al. (2013) stated that social class, regardless of whether it is the cause or the effect of consumption, is closely linked with consumer behaviour and also methods of product marketing (18).

In this study, it was found that opinion leaders play significant positive roles in the behaviour of sports product consumers.

Humphreys and Ruseski (2008) stated that such people can be the opinion leaders, who can be defined as consumers who influence the decisions of others. Information is the primary tool used by sports marketers to influence the behaviour of sport consumers. While ultimately the information is processed by the individual, in many cases, the members of one group or several groups can provide information, interpret or refine it (19).

In this study, it was found that the consumer's family plays a significant positive role in the behaviour of consumers of sports products.

The subjects in this study expressed that when purchasing sport products, usually one of the family members accompanies them; the family opinion is effective in their purchase, and they purchase a product which is accepted by family. Davies and Cline (2005) stated, strongest reference group in modern societies is the 
family. The family's duty towards the individual includes emotional support, providing appropriate lifestyle and strong economy support. Family members influence each other during the life to make decisions about buying products. Researchers suggest sport marketing experts to determine the role of each of the family members in the decision-making process to determine the best way to impress sport consumers to buy products. Identification of the final user of the product for tracking and measuring his/her satisfaction is an important task. For example, the children who use the purchased tickets have the role of user (9).

In this study it was found that reference groups have significant positive roles on the behavior of sport product consumers.

Funk et al. (2009) stated individuals in the sample expressed that purchasing products that the famous athletes use them is very enjoyable for them. They also inclined to buy products which are used by their friends and peers and the opinions of their peers are very effective in purchasing process. Identification of reference groups in the target market helps identify people who ultimately buy sport products. Reference group is a group composed of two or more people that the sport consumer introduces herself/himself as that group, and thus they probably represent common attitudes, values and beliefs (3).

Behnam, Godarzi, and Hamidi (2015) stated Since many people involve in the process of consumer's decision to purchase the sport product or service, the end consumers 'satisfaction will be different from each other and will be reflected in their following purchasing behavior (20). In this study, consumers recommend the use of sport products to others based on levels of satisfaction or dissatisfaction. This issue has countless applications for marketing professionals, because advertising or word of mouth communication plays a very important role in the purchase of sport products. Sport marketing experts must have a general understanding of the various social environments and different social classes to affect consumers. Sport product consumers in the same geographic area may appreciate sport products in different ways based on social class. Some people may consider sport goods based on fashion and status symbols, while others see the sport products as opportunities or threats.

It was also found in this study that culture plays a significant positive role in the behaviour of consumers of sports products.

Ranjbarian, Zabih zadeh, and Berari (2011) observed that culture plays an important role in the success or failure of a particular product or service acceptance. The chance that products fulfil interests compatible with the culture or community members at any point of time is much more acceptable in the market. This implies a consumer culture that determines overall priorities in relation to the activities of various goods (21).

In this study, participants expressed their view that they have to buy goods, check that their fitness matches the norms of society, and purchase a product that meets accepted norms.

In sports consumer behaviour, culture determines the acceptable level of marketing actions. Sports marketing experts should pay attention to the fact that consumers learn how sports culture and which factors influence their decision-making process and solve the problem. The aim behind training sports marketing experts is to recognize cultural differences and devise marketing measures in accordance with its terms of design.

In this study, it was found that religion plays a significant positive role in the behaviour of consumers of sports products. Participants in this study stated that they use products that do not pose any religious problem, and while buying sporting goods, note whether the product in question conforms to religious norms, and purchase products that match their religious attitudes.

\section{CONCLUSION}

The study was conducted for the first time in the sport industry in Iran, before this study, socio-cultural factors affecting sports consumer behavior were not clearly defined, so results of this study can be considered to sport marketers in Iran. The results of the present research suggest that the reasons for purchase are different among different classes of people. The higher classes do purchase not only due to their need but also for leisure and pleasure. Women 
belonging to the upper classes do purchase from big, special and luxury shops, while women of lower chasses do purchase from shops that have cheaper products than the rest of the places. Lower class consumers evaluate goods and products according to their optimality, strength, and comfort than their style, fashion and appearance and likely they less experience many new products, styles and fashions. Instant needs are determents of the consumption behavior of these individuals, while the people in the higher classes focus on long-term goals.

Also, in this study, the participants expressed that they always get help from knowledgeable persons to purchase sporting goods, or informed individuals accompany them in the purchase process. Most of the opinion leaders have more knowledge about a special product or activity, but some individuals may have knowledge and information about the types of products, locations of shopping and other aspects of market information. Such people are called "market mavens". Market mavens provide plenty of information about the wide range of products for others. This information may include knowledge about the quality of the product, selling, usual prices, availability of the product and of the characteristics of the vendors and the other features related to consumers.

In this study results showed when a sport consumer introduces herself/himself as a member of a reference groups he/she usually adapts the norms of that group. Sport marketing experts generally address the characteristics of a reference group to describe a sport product. This fact provides tool for informing the members of the reference group about sport product and justifies the decision to use the same sport product for all members. So researcher suggest sport marketing experts try to influence the members of the group through marketing of sport products based on the need to belong, the need to love and fear of negative evaluation in reference group.

\section{APPLICABLE REMARKS}

- Most important factor affect sport consumer behavior was social class, so this finding suggests that people who are in same social class may have similar sport purchase behavior.

\section{REFERENCES}

1. Abdolmaleki H, Mirzazadeh Z, Allahyari M, Ramezani M. Identify and Analysis of Performance Evaluation Indicators of Iranian Goalball Coaches. Annals of Applied Sport Science. 2015;3(3):43-56.

2. End CM, Foster NJ. The Effects of Seat Location, Ticket Cost, and Team Identification on Sport Fans' Instrumental and Hostile Aggression. North American Journal of Psychology. 2010;12(3):421-32.

3. Funk DC, Filo K, Beaton AA, Pritchard M. Measuring the motives of sport event attendance: Bridging the academic-practitioner divide to understanding behavior. Sport Marketing Quarterly. 2009;18(3):126-38.

4. Abdolmaleki H, Mirzazadeh ZS, Heidari F. The future of human resources in sport organizations with scenario making, the Case study: Developing country of Iran. International Journal of Research in Management. 2015;6(5):41-52.

5. Rahulan M, Troynikov O, Watson C, Janta M, Senner V. Consumer Purchase Behaviour of Sports Compression Garments -A study of Generation Y and Baby Boomer Cohorts. Procedia Engineering. 2013;60:163-9.

6. Hasangholipor Yasory T, Estiri M, Yazdani H, Hosseini F. A Survey of Factors Influencing (University of Tehran) Higher Education Students' Orientation to Sport Events. Journal of Sport Management. 2009;1(3):97213 [Article in Farsi].

7. Nazari M, Ghaderi Abed AH. Developing a Model to Evaluating Effective Factors on Impulse Buying Behavior. Iranian Business Management. 2011;3(10):127-40 [Article in Farsi].

8. Shafizadeh H, Seyedi SI, Ghasemi Dalarsetaghi I. Presentation of Integrated Model of Consumer Behavior in Electronic Shopping. Jounal of Marketing Management. 2013;8(19):13-28 [Article in Farsi].

9. Davies A, Cline TW. A consumer behavior approach to modeling monopolistic competition. Journal of Economic Psychology. 2005;26(6):797-826.

10. Behnam M, Hamidi M, Goudarzi M. The Effect of the Promotion of Free Sport Services on Arousal and Future Intention of Consumers in Advertisement. Journal of Sport Management. 2014;6(2):247-62 [Article in Farsi].

11. Kharazmi E, Forghani Ozrudi M, Amani H. Survey of Determine of Basic Factors Athletes Loyalty Level of National Teams on Sports Brands and Clothes. Sport Management Studies. 2015;6(27):31-46 [Article in Farsi]. 
12. Sadeghi R, Keshkar S, Ghasemi H, Karegar GA. Comparison and Determination the Reasons of Purchasing Foreign Sport Products from Producers, Sellers and Consumers Viewpoints. Applied Research of Sport Management. 2013;2(6):21-32 [Article in Farsi].

13. Behnam M. The influence of free sport service promotion on pleasure and consumer's attitude in advertisement. Sport Management Studies. 2015;7(28):13-32 [Article in Farsi].

14. Tatt KE. Factors Influencing Consumer Buying Behavior of Luxury Branded Goods. Malaysia: Universiti Sains Malaysia; 2010.

15. Yee WF, Sidek Y. Influence of brand loyalty on consumer sportswear. International Journal of Economics and Management. 2008;2(2):221-36.

16. McLaren CB. A Dynamic Model of Consumer Behavior. California, USA: University of California Riverside; 2012.

17. Anastasiadou SD. A Structural Equation Model Describes Factors Affecting Greek Students' Consumer Behavior. Procedia Economics and Finance. 2014;9:402-6.

18. Hassangholipour T, Hashemi-Njad S-M, Azizan MJ, Seyghali M. Identification and ranking measures affecting electronic shopping in Iran. Journal of Management Futures Research. 2013;2.2(2):1-14 [Article in Farsi].

19. Humphreys BR, Ruseski J, editors. The size and scope of the sports industry in the United States. 10th annual IASE Conference Papers; 2008; Gijón, Spain: International Association of Sports Economists (IASE).

20. Behnam M, Godarzi M, Hamidi M. The influence of advertising appeal on future intention and consumer's attitude toward advertisement in sport service. Sport Management Studies. 2015;7(30):35-54 [Article in Farsi].

21. Ranjbarian B, Zabih zadeh K, Berari M. Status and Role-Relaxed models Consumption Patterns among Students of University of Isfahan. Women in Development \& Politics. 2011;9(2):155-80 [Article in Farsi]. 